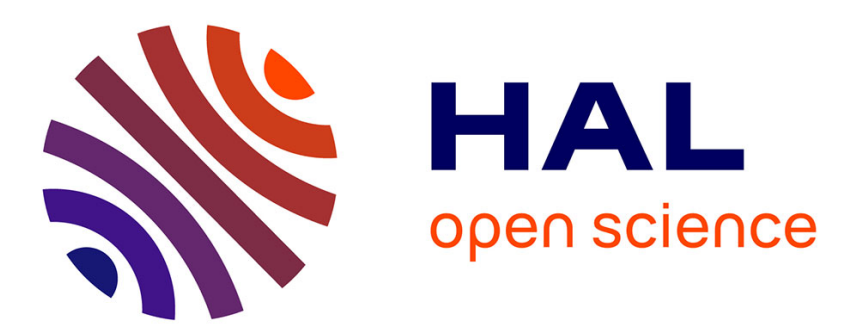

\title{
Development and Characterization of Thinned PZT Bulk Technology Based Actuators Devoted to a 6-DOF Micropositioning Platform
}

Amine Benouhiba, Djaffar Belharet, Alex Bienaime, Vincent Chalvet, Micky Rakotondrabe, Cédric Clevy

\section{To cite this version:}

Amine Benouhiba, Djaffar Belharet, Alex Bienaime, Vincent Chalvet, Micky Rakotondrabe, et al.. Development and Characterization of Thinned PZT Bulk Technology Based Actuators Devoted to a 6-DOF Micropositioning Platform. Microelectronic Engineering, 2018, 97, pp.53 - 60. hal-02867839

\section{HAL Id: hal-02867839 \\ https://hal.science/hal-02867839}

Submitted on 15 Jun 2020

HAL is a multi-disciplinary open access archive for the deposit and dissemination of scientific research documents, whether they are published or not. The documents may come from teaching and research institutions in France or abroad, or from public or private research centers.
L'archive ouverte pluridisciplinaire HAL, est destinée au dépôt et à la diffusion de documents scientifiques de niveau recherche, publiés ou non, émanant des établissements d'enseignement et de recherche français ou étrangers, des laboratoires publics ou privés. 


\title{
Microelectronic Engineering
}

\section{Development and Characterization of Thinned PZT Bulk Technology Based Actuators Devoted to a 6-DOF Micropositioning Platform}

\author{
Amine Benouhiba, Djaffar Belharet, Alex Bienaimé, Vincent Chalvet, Micky Rakotondrabe and Cédric Clévy \\ * Corresponding author \\ All authors are with FEMTO-ST Institute, Univ. Bourgogne Franche-Comté/CNRS, 25000 Besançon, France. \\ name.surnamedfemto-st.fr
}

\begin{abstract}
Piezoelectric actuators are widespread in the design of micro/nanorobotic tools and microsystems, as they have a very interesting electromechanical coupling factor, in addition to their high dynamics and resolution performances. Studies toward the integration of such actuators in complex micromechatronic systems require the size reduction of these actuators while retaining a wide range of performances. Two main fabrication processes are currently used for the fabrication of piezoelectric actuators, providing very different behaviors: (i) the use of a bulk layers and (ii) the use of thin film growth. In this study, we propose to develop micropositioning actuators and platform whose performances are a trade-off between the performances from these two technologies. The proposed trade-off technology allows the development of microsystems with high stiffness, high torque and high dynamics (from technology (i)), as well as, large motion, low voltage and small size (from technology (ii)). Using this technology we designed and fabricated a thick film PZT platform containing eight unimorph beam bending actuators. The Platform allows a high level of performances, both in the static (displacement) and dynamic (first resonance frequency) regimes. The purpose of the fabricated platform is to improve the micromanipulation and microassembly processes, to the point where approaching and manipulating very small object with a high precision will be a very fast and simple operation. Theses devices were obtained through a room temperature mechanical thinning of a PZT thick layers, after the deposition of Nickel on the bottom side. The piezoelectric beam bending actuators have a $80 \mu \mathrm{m}$ thick PZT layer on top of a $10 \mu \mathrm{m}$ thick Nickel layer, a length of $5 \mathrm{~mm}$ and a width of $0.5 \mathrm{~mm}$. Experimental characterization has shown that the static displacements obtained are in excess of $1.33 \mu \mathrm{m} / \mathrm{V}$ and the resonance frequencies are up to $1814 \mathrm{~Hz}$, which are very convenient in high dynamics micropositioning applications such as microrobotics and microassembly tasks.
\end{abstract}

Keywords: piezoelectric, micro-fabrication, unimorph beam bending actuator, PZT thinning, Laser etching.

\section{INTRODUCTION}

Lead Zirconate Titanate (PZT) piezoelectric materials are widespread in Micro-ElectroMechanical System (MEMS) applications because of their exceptional electromechanical coupling factor, high dynamics and high resolution performances. Piezoelectric ceramics (especially PZT) are able to work under most harsh environmental conditions, including oil, dirt, and most chemical atmospheres. They are not easily damaged, by severe shock and/or vibration, and they perform well over a wide temperature range [1]. They offer a wide range of applications from classical ultrasonic devices [2], [3], [4], [5], [6], fuel injection systems [7], [8], [9], [10], smart structures [11], [12], [13], [14], high precision positioning equipment [15], [16], [17] for electronic manufacturing and other domains, energy harvesting [18], [19], [20], [21], [22], [23], [24] and gas sensing [25]. These systems are particularly supported by the cleanroom technology, using the increasing possibility of micro fabrication techniques, to integrate active materials and designs with compliant structures. However, the integration of different physical components in such a miniaturized system while allowing a high performances can be a real challenge, such as, having a large range of motion/deformation, high bandwidth, high stiffness, high resolution, small size, low energy consumption and sensing possibility, all within the same actuator. This is why, piezoelectric ceramics are usually the materials of choice when it comes to the miniaturized systems, thanks to their abilities to satisfy most of the needed requirements, their availability and their easy manufacture. There is a fair number of designs and structures of piezoelectric systems, but one of the most used structures is the beam bending actuator structure. These actuators have cantilever structure generally clamped-free. These kinds of actuators can be utilized in scanning probe microscopes [26], [27], precise and highly dynamic positioners in micromanipulation and microassembly [28], [29], or actuators for laser scanning in medical applications [30]. The beam bender structure can also be utilized as sensors, opening the door to promising studies in mass detection sensors, microscale force sensors and biosensors [31]. There are two main ways to fabricate the beam benders:

Bulk Technology: they are made of bulk layers of piezoelectric ceramic materials (typically more than $200 \mu \mathrm{m}$ ), giving them a high inherent stiffness, good dynamics (KHz frequency range) but in counterpart small output displacements (typically a few tens of $\mu \mathrm{m}$ ). Moreover, due to the thickness of such actuators, the required voltages to achieve the needed displace- 


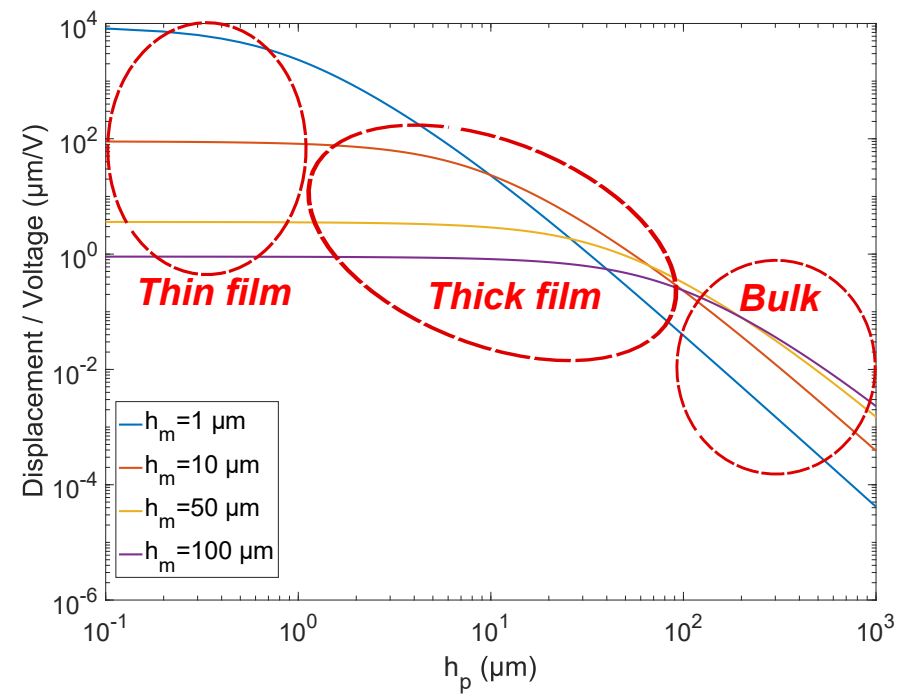

(a)

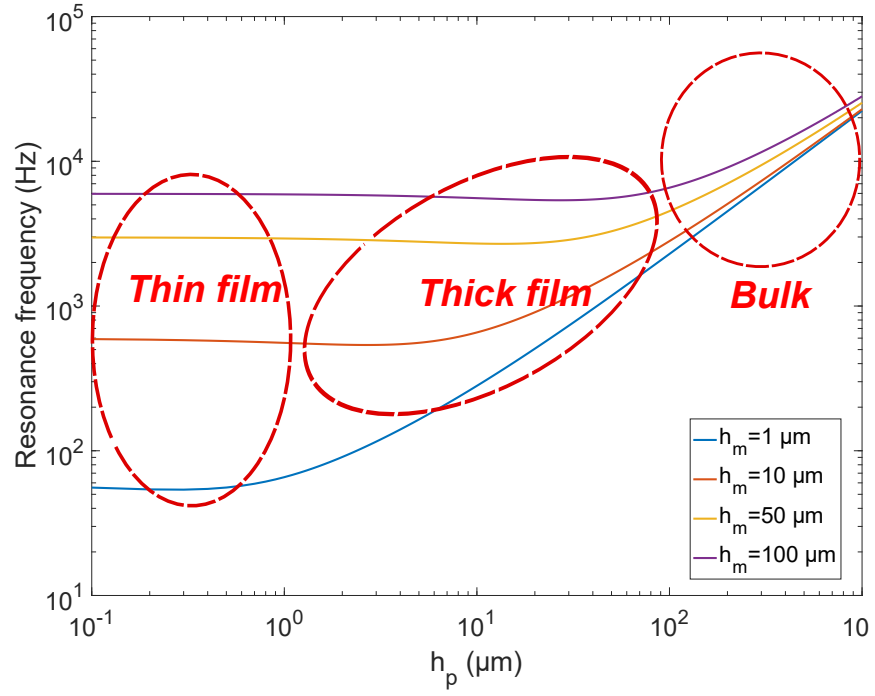

(b)

Fig. 1. Theoretical (Ballas's linear model [32]) (a) displacement and (b) first resonance frequency for different kinds of unimorph beam bending actuator: influence of $\left(h_{p}\right)$ the PZT layer thickness for four Nickel layer thicknesses $\left(h_{m}\right)$, with a length $\mathrm{L}=4.5 \mathrm{~mm}$.

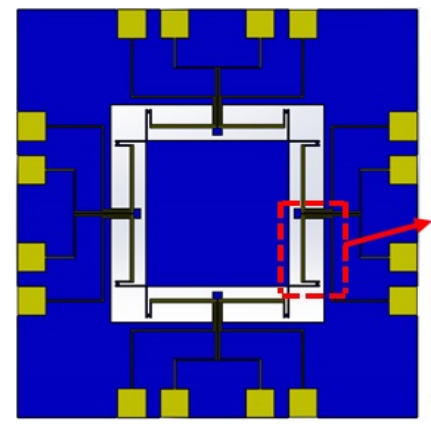

(a)

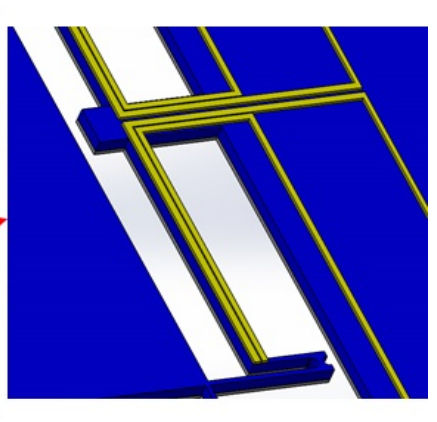

(b)
Fig. 2. The design of the platform (a) the full design with eight beam bending actuators and (b) a single beam bending actuator: There are two gold top electrodes (yellow) for each of the eight PZT (blue) based bean bending actuators, in addition to the bottom electrode (ground)

ments is very high (a few hundreds volts). Consequently, these actuators are mostly, bulky, and have to be very long (tens of $\mathrm{mm}$ at least), to reach the appropriate needed displacements.

Thin Film Technology: this technology is quite the opposite of the first one: instead of using bulk piezoelectric ceramic materials, they are deposited in a very thin layers (typically few $\mu \mathrm{m}$ ), and considering their thickness, higher electrical fields than bulk actuators are obtained for the same driving voltage. Therefore, these actuators can reach very high displacements (a few hundreds $\mu \mathrm{m}$ ) for low voltages and for smaller lengths(typically less than one $\mathrm{mm}$ ). In counterpart, they have a low stiffness, which makes them inefficient for structures that require a high torque. Furthermore, they are characterized by low dynamics (much smaller than one $\mathrm{KHz}$ ). In attempt to close the gap between the two technologies, the Thick Film Technology [31] was adopted in this work. With actuators thicknesses ranging from $5 \mu \mathrm{m}$ to $150 \mu \mathrm{m}$, this technology makes use of the advantages offered by both technologies, thin film technology (large motions, low voltage, small sizes), and bulk technology (high stiffness and torque, high dynamics).

Nonetheless, in order to integrate PZT actuators, a lot of process flow approaches were proposed [33]. The common point of these proposed fabrication methods is the use of bilayered structures: an active layer (piezoelectric) and passive layer. The performances of these devices are correlated to the ratio of the thicknesses of the both layers (see fig. 1). Moreover, using the thick film technology, opens the door for a lot of new technical challenges during the fabrication process. Such as, high mechanical stress between the two layers, long and difficult fabrication steps and inefficient process flow. Therefore, in this paper, a direct process flow was proposed, which has two major distinctions from the classic microfabrication processes:

1. No gluing of any kind of the PZT layer to a support layer (usually made of $\mathrm{Si}$ wafer) is required, which is normally a necessary step considering that without the support layer the PZT layer will not survive the process flow;

2. The use of Ni layer has a triple purpose. A support layer during the fabrication process, a passive layer for the unimorph actuators and also a bottom electrode (ground).

As a result, the number of the fabrication steps was reduces, significantly. Furthermore, a second and an even simpler and shorter process flow, based on microfabrication and laser etching technologies, was introduced as well, in this paper.

The aim of the paper is to propose a direct process flow, for the fabrication of a PZT based microassembly/micromanipulation platform. The purpose of the latter, is to improve the micromanipulation and microassembly processes, to the point where approaching and manipulating very small objects with a high precision will be a very fast and simple operation. In section II, the adopted design and the utilized materials is introduced. Then, using Finite Element Methods (FEM) simulations, the operating mechanism of the platform is ex- 


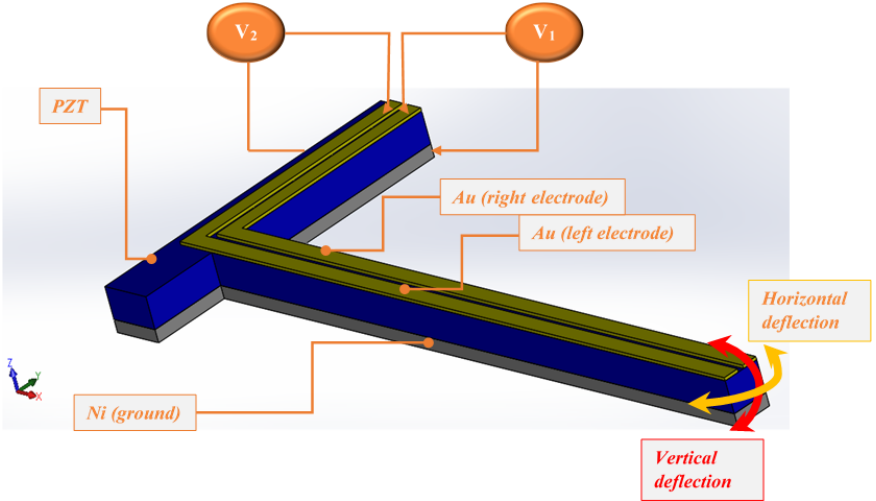

Fig. 3. The actuation mechanism of a single beam bending actuator with two top electrodes and a bottom electrode (ground).

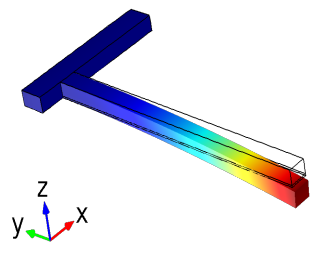

(a)

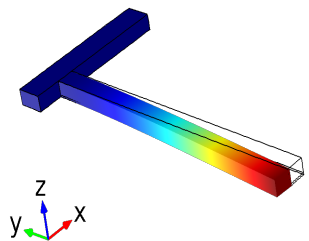

(b)
Fig. 4. A representation of the actuation mechanism of the unimorph beam bending actuator (a) for a vertical displacement (when the voltage applied to both of the top electrodes is the same) (b) for a horizontal displacement (when the voltage applied to one of the top electrodes is the opposite of the other one).

plored. In section III, the proposed direct process flows, is described, and the final devices are presented. In section IV, an experimental validation of the principle is conducted. The results (displacements and resonant frequencies) are compared to the FEM simulations, and then both presented. In section V, some projects about the characterization of the full platform and its applications are given.

\section{Presentation of the Design And of its FUNCTIONING}

The design is a platform used for micromanipulation and/or microassembly applications. This new platform was designed with the purpose of making the micromanipulation processes easier, simpler and more accurate. The object to be manipulated will be placed on top of the platform, then the latter moves the object with a high precision and accuracy which otherwise can't be achieved with commercially available positioning systems. The platform itself is made of eight beam bending piezoelectric actuators (as shown in fig. 2). The actuators are unimorph beam bending actuators and made of a piezoelectric active layer and an elastic passive layer, with electrodes. The top electrodes are made of a very thin layer of $\mathrm{Au}$, because of its high electrical proprieties and resistance to oxidation. The active layer is made of PZT, as in the case of piezoelectric ceramic materials, coupling proper design with the right

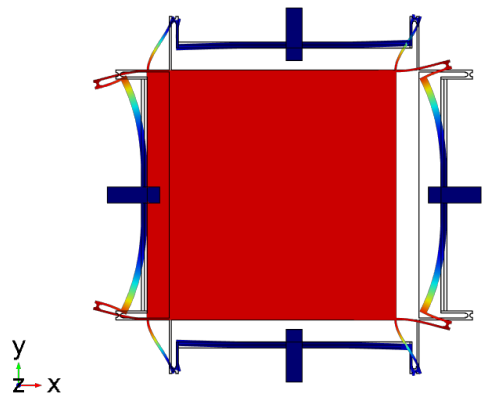

(a)

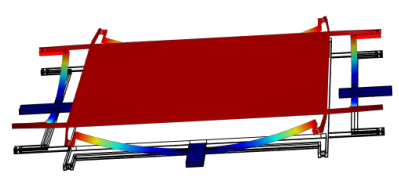

$x+\frac{z}{y}$

(b)

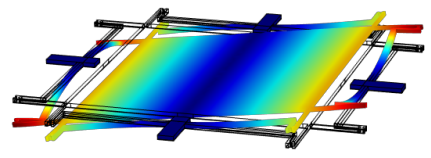

$\stackrel{\mathrm{Z}}{\mathrm{y}} \mathrm{x}$

(c)

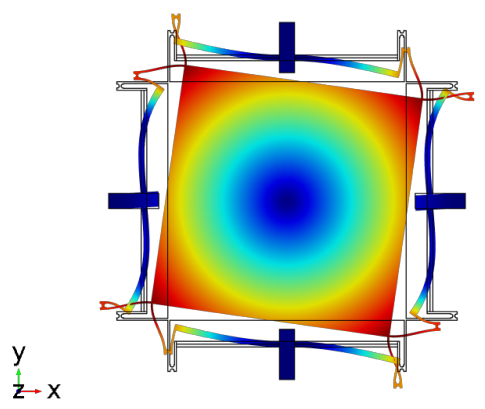

(d)

Fig. 5. The actuation mechanism of the full platform (a) in the plan $(X, Y)$ (b) along the $\mathrm{Z}$ axis (c) the rotation around the $\mathrm{X} / \mathrm{Y}$ axis and (d) the rotation around $\mathrm{Z}$ axis.

selection of materials allows for a very interesting range of properties: A dynamic behavior, ranging from lower than 1 $\mathrm{Hz}$ to above several $\mathrm{MHz}$, a static behavior (displacements) in 
the $\mathrm{mm}$ range and force variation, from $\mathrm{mN}$ to $\mathrm{kN}$.

Finally, a metal passive layer was chosen because no bottom electrode is needed, which was not the case in the old process made also by Bienaimé et al [31], where a Si layer was used as a passive material and $\mathrm{Au}$ as a top and a bottom electrodes, thus, resulting in a few additional steps in the fabrication process the devices. The metal chosen in this case is Ni. The choice of $\mathrm{Ni}$ is based on it's stiffness. The Ni deposited is obtained by the electroplating process which permits to obtain thick layers (10 to $15 \mu \mathrm{m}$ thickness), it is not possible to obtain such values by using sputtering or evaporator systems. Depending on the thickness of the PZT layer (20 to $100 \mu \mathrm{m}$ thick), the Ni layer thickness must be thick enough to generate high displacements.

\section{A. Presentation of 2-DOF unimorph actuator}

The platform contains 8 unimorph beam bending actuators. Each actuator has 3 electrodes, 2 top electrodes, one on the right and one on the left, and a bottom electrode (the ground), as shown in fig. 3. If the same driving voltage with the same sign (meaning, $V_{1}=V_{2}$ ), is applied to both top electrodes, the actuator will induce vertical deflection (z) (fig. 4.A), but if the same driving voltage is applied, with opposite signs $\left(V_{1}=-V_{2}\right)$, the actuator will bend with horizontal deflection (y) (fig. 4.B).

\section{B. Presentation of the 6-DOF platform based on unimorph actuators}

The displacements of the platform are achieved by combining the deflections of the 8 beam bending actuators. Moreover, the overactuation ( 8 actuators for $6 \mathrm{DOF}$ ) allows a high quality guiding of the platform, to obtain a high quality linear motion. So, basically the platform can move up and down, in z-direction (piston motion) using the vertical deflection of all the 8 actuators. Likewise, it can move in y-direction using the horizontal deflection of 4 actuators, and in x-direction using the horizontal deflection of the remaining 4. Moreover, the same principle is also valid for the 3 rotations: combining the right vertical and horizontal deflections, will lead the desired rotation angle, as shown in tab. I. The platform has 6 degrees of freedom, 3 translations and 3 rotations, as shown in fig. 5.

TABLE I

THE ACTIVATED ACTUATORS FOR ALL OF THE PLATFORM'S DISPLACEMENTS.

\begin{tabular}{lc|c|c} 
& $\begin{array}{c}\text { Number of the } \\
\text { activated actuators }\end{array}$ & $\begin{array}{c}\text { horizontal } \\
\text { deflection }(\mathrm{X} / \mathrm{Y})\end{array}$ & $\begin{array}{c}\text { vertical } \\
\text { deflection }(\mathrm{Z})\end{array}$ \\
\hline $\begin{array}{l}\text { Displacement } \\
\text { along X/Y axis }\end{array}$ & 4 & 4 & - \\
\hline $\begin{array}{l}\text { Displacement } \\
\text { along Z axis }\end{array}$ & 8 & - & 8 \\
\hline $\begin{array}{l}\text { Rotation around } \\
\mathrm{X} / \mathrm{Y} \text { axis }\end{array}$ & 4 & - & 4 \\
\hline $\begin{array}{l}\text { Rotation around } \\
\mathrm{Z} \text { axis }\end{array}$ & 4 & 4 & - \\
\hline
\end{tabular}
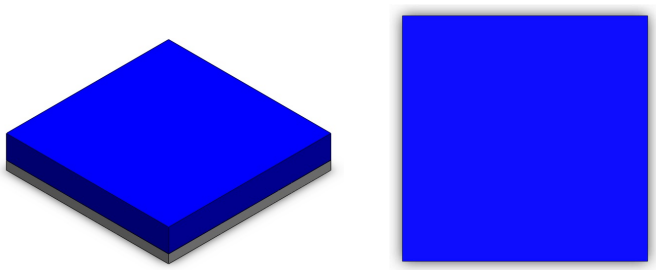

(a)
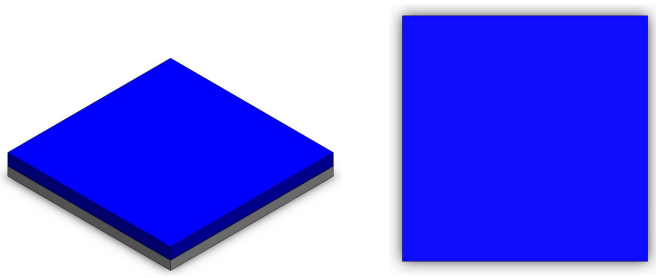

(b)
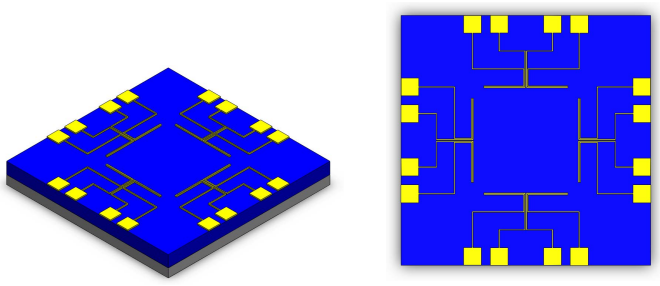

(c)
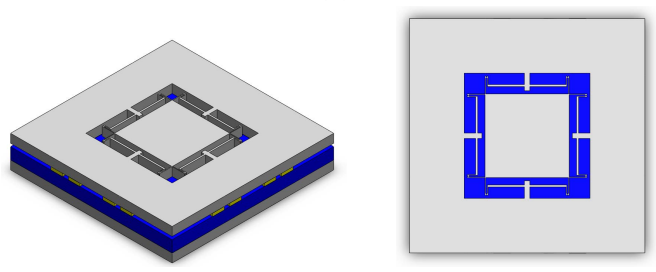

(d)
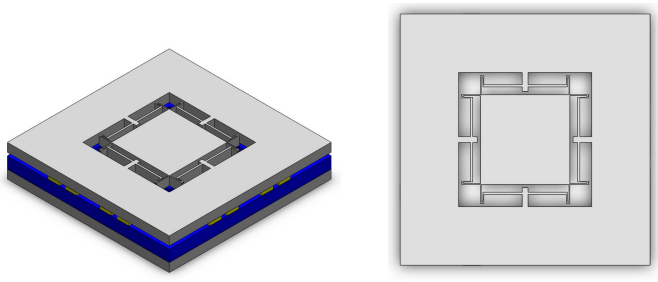

(e)
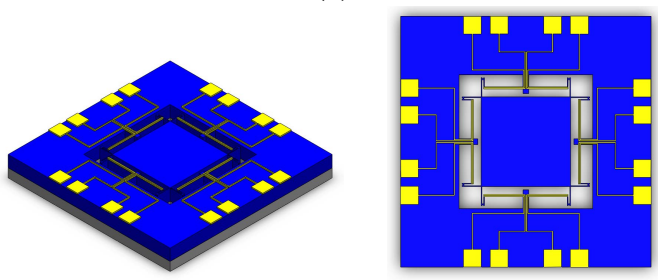

(f)

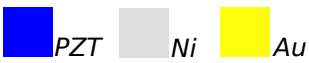

Fig. 6. The fabrication of the 6-DOF micropositioning platform using microfabrication techniques (left: side view, right: top view) (a) the deposition of a nickel layer on the bottom side of a PZT plate by an electroplating process, then (b) the PZT plate was mechanically thinned and polished, before the deposition of (c) the gold top electrodes on the top side, followed by (d) the deposition of a nickel mask, which is needed for the next step (e) the plasma etching and finally (f) the etching nickel mask was chemically removed. 


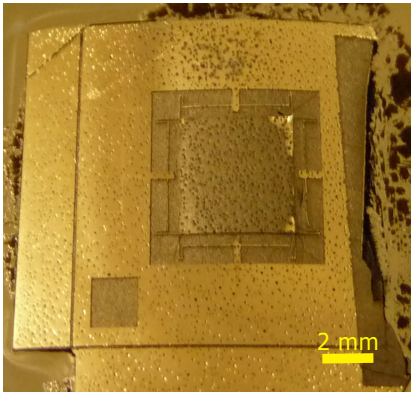

(a)

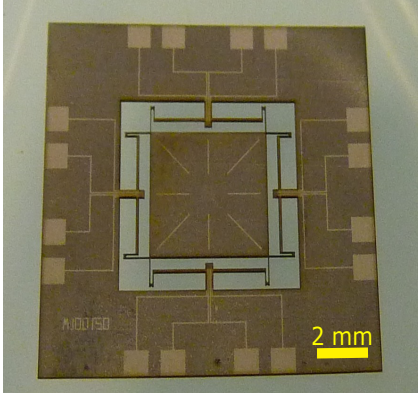

(b)
Fig. 7. A platform fabricated using (a) plasma etching process and (b) laser etching process, each actuator of the platform is $2 \mathrm{~mm}$ long, $120 \mu \mathrm{m}$ wide and $95 \mu m$ thick.

\section{PROCESS FLOW}

In this work, the objective is to take advantage of the excellent qualities that a bulk ceramic (PZT) piezoelectric actuator can offer to the multi-DOF positioning system. Several challenges are to be considered, which mainly, would be to find a way to overcome the long and complex operations given by the standard microfabrication process for such devices. In this paper, a direct microfabrication process is proposed. Several approaches have been proposed: no bonding of PZT plates to Si wafers. Usually in this kind of processes, bonding the the PZT plate to a Si wafer is a standard step in the process. It is very critical step, since the PZT layer is very fragile and can be broken easily. However, it also requires a few additional steps, which makes achieving a fully functioning platform highly time consuming and quite challenging. Furthermore, the proposed approaches consist also of utilizing a passive metal layer of Ni. The metal layer has a triple purpose. (i) to act as a passive layer for the unimorph beam bending actuators. (ii) to prevent the fragile and very thin PZT layers from breaking, so it will be possible to manipulate the layers throughout the whole steps of the fabrication process. (iii) to be used also, as bottom electrode, hence, no need for the deposition of a conductive layer on the bottom side (such as, gold for example). These changes enabled the execution of the full process flow, with very few steps. Finally, in another attempt to push the frontiers of the this process to the limit, laser technology was adopted as well, for the etching step, making it possible for the process flow to be simple, short, with high success rate and high reproducibility.

\section{A. Process flow using the micro-fabrication techniques}

In the first attempts a process flow based only on microfabrication technology was used, from beginning to end (as shown in fig. 6). PZT plates with 2.5 inch in diameter and $180 \mu m$ in thickness were utilized. First, a $15 \mu m$ thick layer of $\mathrm{Ni}$ was electrodeposited on the bottom side of the PZT plates, using a photoresist mask (6m AZ9260). We started with $\mathrm{Ni}$ because, otherwise, once the PZT layer is thinned (step b-fig. 6), it will be too fragile for future steps. Next, is the mechanical thinning and polishing of the PZT plates to a final thickness of $80 \mu \mathrm{m}$. Then, a 10/200 nm thick layers of $\mathrm{Ti} / \mathrm{Au}$ were deposited, respectively, on the top side of the plates
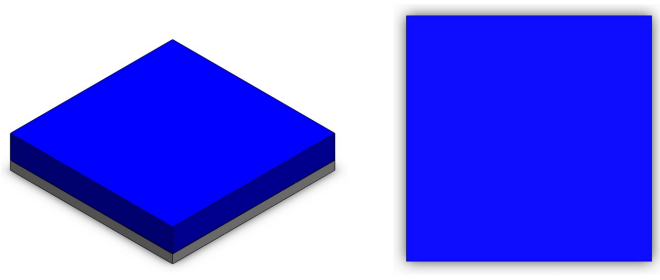

(a)
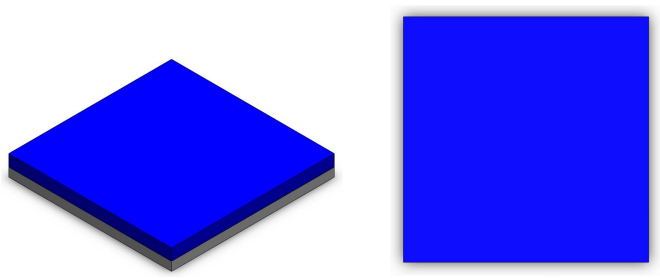

(b)
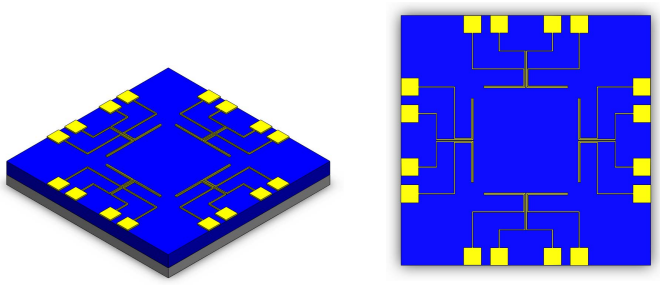

(c)
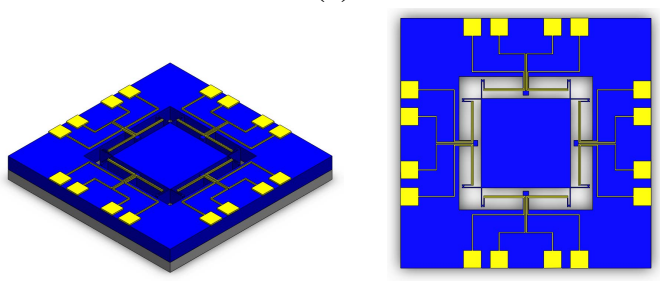

(d)

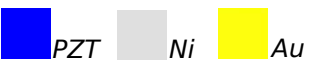

Fig. 8. The fabrication of the 6-DOF micropositioning platform using microfabrication and alternative techniques (left: side view, right: top view) (a) the deposition of a nickel layer on the bottom side of a PZT plate by an electroplating process, then (b) the PZT plate was mechanically thinned and polished, before the deposition of (c) the gold top electrodes on the top side and finally (d) the device was etched using high precision laser machining.

(top electrodes). The deposition step was done using cathodic sputtering and the lift-off techniques, for better resolution. Ti was chosen as seed layer, in order to avoid the removal of the top electrodes, in the chemical etching later on. After, a $\mathrm{Ni}$ mask was electrodeposited on the top side for the plasma etching. The mask is also $10 \mu \mathrm{m}$ thick, since the selectivity of Ni to the PZT is around 1:15. Then, to prepare for the the Plasma etching, the plates were glued by a crystalbond agent to a Si carrier wafer, and using Deep Reactive Ion Etching (DRIE) technique, the Plasma etching was achieved. Despite the fact that, the crystalbond agent can withstand the harsh conditions of the plasma etching, it can easily be removed afterwards, using water at $80^{\circ}$. Finally, the bottom side of the plates were covered using photoresist (the bottom Ni layer), and the Ni mask (top Ni layer) was chemically removed. The final device can be seen in fig. 7.A. 


\section{B. Process flow combining micro-fabrication and alternative techniques}

Despite the fact that the developed process above is simple and fully functioning (fig. 6). It still has some drawbacks, such as: The double-sided alignment, between the Ni mask (top $\mathrm{Ni}$ layer) and the Ni passive layer (bottom Ni layer), which can be very technically challenging. Moreover, During the DRIE process, mechanical stress is generated between the PZT active layer and the Ni passive layer. As a result, a slight bending of the layers can be observed. In addition to the fact that, it still there is a room for the number of steps of the process flow to be made even shorter. Therefore, a second direct process flow using laser etching technique [34], [35] instead of plasma etching [36], was proposed. This made the fabrication process even simpler, faster and more efficient. The process (fig. 8) starts the same as above, with the electrodeposition of a Ni passive layer on the bottom side of the PZT plates, which as already mentioned acts as a support layer during the fabrication process. However, in this case, no need for a photoresist mask, the Ni is deposited full plate, to be etched later on with the PZT layer, during the laser etching step. Then, the cathodic sputtering of the top electrodes on the top side of the PZT plates (10/200 nm thick layers of Ti/Au, respectively). Finally, the laser etching of both the PZT active layer and the $\mathrm{Ni}$ passive layer at once, which ensures a very good alignment between the too layers, each time (see fig. 7.B), without inducing any residual mechanical stress.

TABLE II

DIMENSIONS.

\begin{tabular}{cccc} 
& Length $(\mathrm{mm})$ & width $(\mathrm{mm})$ & PZT/Ni thicknesses $(\mu m)$ \\
\hline Beam 1 & 5 & 0.5 & $80 / 5$ \\
\hline Beam 2 & 5 & 0.5 & $80 / 10$ \\
\hline
\end{tabular}

TABLE III

PLATFORM RESULTS.

\begin{tabular}{lc|c} 
& Experimental results & FEM simulation \\
\hline Displacement along & - & 0.4 \\
$\mathrm{X} / \mathrm{Y}$ axis $(\mu \mathrm{m} / \mathrm{V})$ & & \\
\hline $\begin{array}{l}\text { Displacement along } \\
\mathrm{Z} \text { axis }(\mu \mathrm{m} / \mathrm{V})\end{array}$ & 0.53 & 0.3 \\
\hline $\begin{array}{l}\text { Rotation around } \\
\mathrm{X} / \mathrm{Y} \text { axis }(\text { degrees } / V)\end{array}$ & & $5 \times 10^{-3}$ \\
\hline $\begin{array}{l}\text { Rotation around } \\
\mathrm{Z} \text { axis }(\text { degrees } / \mathrm{V})\end{array}$ & - & $4.8 \times 10^{-3}$ \\
\hline
\end{tabular}

\section{VALIDATION OF THE PRINCIPLE}

To validate the approach discussed above, two type of systems were fabricated, then characterized. First, Simple beam bending actuators, as they represent the basic units for the platform. Secondly, the full platform, since this approach was developed mainly to overcome, the challenges and difficulties, provoked by the fabrication of such systems.

\section{A. simple beam actuators}

Two different simple beam bending actuators were released, each with a different thickness of the Ni passive layer.
Depositing thick layers of $\mathrm{Ni}$ can generate some stress on the PZT layer, so comparing two beams with different Ni layer thicknesses, can shed some light on its influence, as well as its effect on the performances of the actuators. Both simple beam bending actuators in tab. IV, were fabricated using laser etching. Then, they were mounted in the characterization setup, by two small parts, which were screwed closer together to act as a gripper, as shown in fig. 9. The electrical contacts were made, using gold coated contact tips. A laser displacement sensor, Keyence (LC-2420) was utilized to measure the bending of the cantilever actuators. It was tuned to have a measurement resolution of $10 \mathrm{~nm}$, a precision of tens of nanometer and a range of $\pm 150 \mu \mathrm{m}$. The experimental results were compared to theoretical results, and they are presented in tab. IV. Two different types of theoretical results were presented. The results of the analytical model, which is based on Ballas's linear model [32], and the results of finite element method (FEM) simulations. Both beam bending actuators have high static/dynamic behaviors, thanks to the characteristics offered by the thin bulk technologies, which also means that the mechanical stress created by the $\mathrm{Ni}$ layer has little to none influence on the performances of the actuators. The theoretical results (displacements) were slightly smaller than the experimental ones, because the linear theoretical model (Ballas's linear model), do not take into account the hysteresis phenomenon fig. 10. For small voltages, both results are very close (the model and the experimental results), then when the voltage goes higher, the experimental displacement starts to deviate.

\section{B. Platform}

To characterize the platform, the laser etched devices were utilized, as they were slightly better (they had zero damage), and also because they can be somewhat easier to reproduce. For the sake of convenience, the characterization was limited to the the vertical displacement of the platform (the displacement in the Z-axis direction, as shown in fig. 5.B). The full characterization of the platform can be very helpful, to determine the performances of the platform as micromanipulation or microassembly device. However, the characterization of the platform is an ongoing work (measuring all of these degrees of freedom is no way near a simple task), which goes behind the scope of this paper, since the only concern of the section is to validate the developed direct process flow.

In order to characterize the vertical displacement of the platform, the bottom face of the latter (the bottom electrode) was glued on top of a small gold coated PCB chip $(28 \times 28$ $m m^{2}$ ), using a conducting glue (silver based glue), then cured for 48 hours at room temperature. Next, the top electrodes of the platform were connected using wire bonding. Finally using laser sensor the vertical displacement of the platform was measured (fig. 11). The results were compared to the FEM simulations and presented in tab. III. Both experimental result shown by the platform and the simple beam bending actuators tend to validate the approach of the paper. 
TABLE IV

UNIMORPH SIMPLE BEAM RESULTS.

Beam 1

Beam 2

\begin{tabular}{cccc|ccc}
\hline & Experimental results & FEM simulation & Ballas's model & Experimental results & FEM simulation & Ballas's model \\
\hline Displacement $(\mu \mathrm{m} / \mathrm{V})$ & 0.48 & 0.76 & 0.52 & 1.33 & 1.29 & 0.78 \\
\hline Resonant frequency $(\mathrm{Hz})$ & 1607 & 1662 & 1652 & 1814 & 1771 & 1819 \\
\hline
\end{tabular}

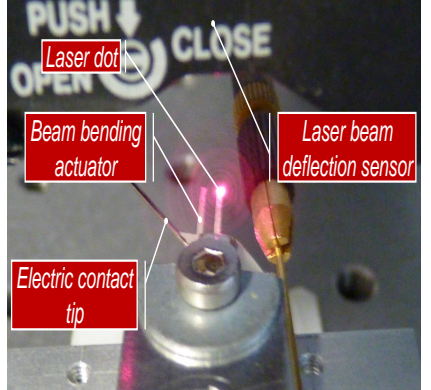

Fig. 9. Experimental setup for unimorph simple beam actuators: laser machined beam actuators were fixed using a gripper like device, furthermore two gold coated contact tips were used for the electrical contact (one for each side) and finally a laser displacement sensor was utilized to measure the displacements of the cantilevers.

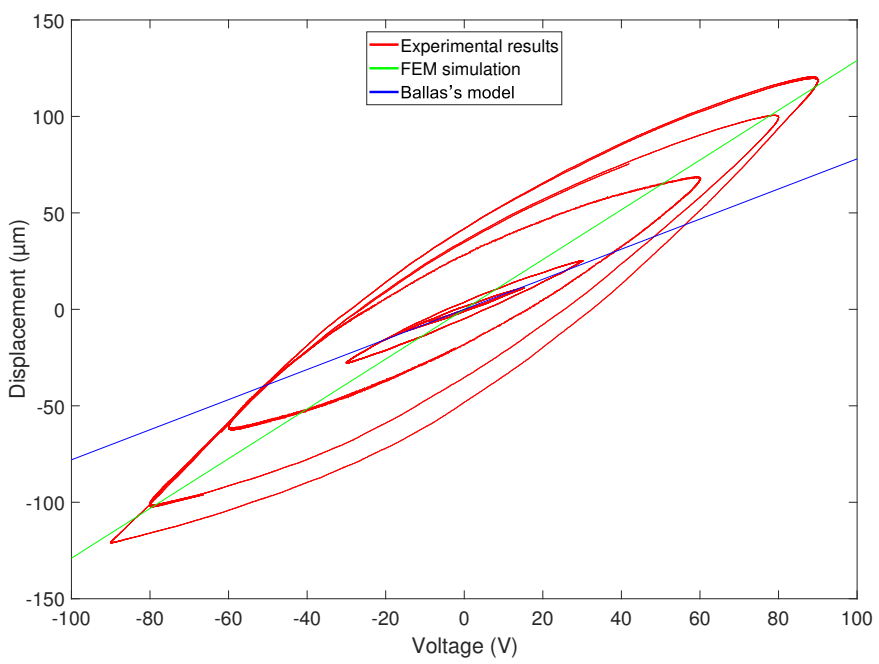

Fig. 10. The variation of the displacement by the voltage of beam 2, the hysteresis was obtained at a frequency of $0.1 \mathrm{~Hz}$.

\section{CONCLUSION}

The objective of the paper was the development of a direct process flow, for the fabrication of a micromanipulation and/or microassembly, miniaturized platform, for PZT thick film technology.

The new process flow is very simple, which makes it less time consuming, less complicated and highly efficient. Furthermore, the laser etching, enables the process to become even simpler, and to have even less technical challenges. The characterization of the $5 \mathrm{~mm}$ long beam bending actuators (80 $\mu m$ PZT layer and $10 \mu m$ Ni layer), shows that the generated displacement is $1.33 \mu \mathrm{m} / \mathrm{V}$, which is, as expected, slightly higher than the results given by Ballass linear model. It also shows that the first resonant frequency is of a value of 1814

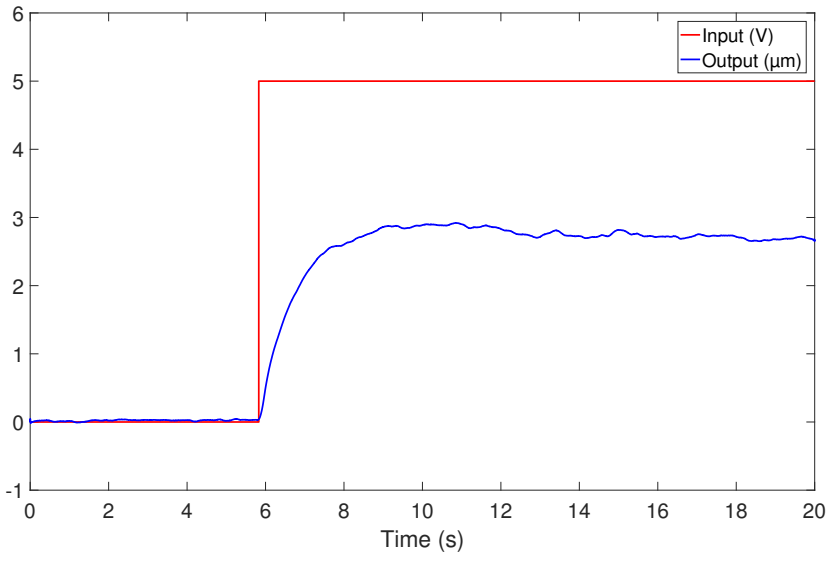

Fig. 11. The vertical deflection of the Micropositioning platform in Zdirection in response to a step voltage input of $5 \mathrm{~V}$.

$H z$. Moreover, the approach used here, enables the realization of very complex MEMS architectures in very fast, accurate and reliable way. The conducted experimental work also validates the high performances that can be obtained (large motions, high dynamics) for very small devices, which allows, high integration potential and high accuracy for robotic application.

The next step is the full characterization of the platform. The results we did get from the simple beam bending actuators are very promising. Also, going toward thinner PZT plates (10 to $20 \mu \mathrm{m}$ ) would allow the full exploitation of the advantages given by the thick film technology, which can be feasible, using the direct process flow.

\section{ACKNOWLEDGMENT}

This work was supported by the french RENATECH network and its FEMTO-ST technological facility, Labex ACTION and ANR project COLAMIR (ANR-16-CE10-0009).

\section{REFERENCES}

[1] J. F. Tressler, S. Alkoy, and R. E. Newnham, "Piezoelectric sensors and sensor materials," Journal of electroceramics, vol. 2, no. 4, pp. 257-272, 1998.

[2] Z. Yang, H. Goto, M. Matsumoto, and R. Maeda, "Active micromixer for microfluidic systems using lead-zirconate-titanate (pzt)-generated ultrasonic vibration," Electrophoresis, vol. 21, no. 1, pp. 116-119, 2000.

[3] P. W.-P. Chu, C.-P. Chong, H. L.-W. Chan, K. M.-W. Ng, and P. C.$\mathrm{K}$. Liu, "Placement of piezoelectric ceramic sensors in ultrasonic wirebonding transducers," Microelectronic engineering, vol. 66, no. 1-4, pp. 750-759, 2003.

[4] P. Muralt, N. Ledermann, J. Paborowski, A. Barzegar, S. Gentil, B. Belgacem, S. Petitgrand, A. Bosseboeuf, and N. Setter, "Piezoelectric micromachined ultrasonic transducers based on pzt thin films," IEEE transactions on ultrasonics, ferroelectrics, and frequency control, vol. 52, no. 12, pp. 2276-2288, 2005. 
[5] D. Sun, S. Wang, S. Hata, J. Sakurai, and A. Shimokohbe, "Driving mechanism and experimental realization of a cylindrical ultrasonic linear microactuator," Microelectronic Engineering, vol. 86, no. 4-6, pp. 12621266,2009

[6] C.-P. Wang, G.-B. Wang, and Y. Ting, "Analysis of dynamic characteristics and cooling performance of ultrasonic micro-blower," Microelectronic Engineering, 2018.

[7] M. Mitsuyasu and T. Takahashi, "Drive circuit for an electrostrictive actuator in a fuel injection valve," Aug. 25 1987, uS Patent 4,688,536.

[8] T. Tomoda, S. Sasaki, D. Sawada, A. Saito, and H. Sami, "Development of direct injection gasoline engine-study of stratified mixture formation," SAE Technical Paper, Tech. Rep., 1997.

[9] M. Akaki, Y. Yamada, N. Oota, M. Mitsuyasu, and D. Sawada, "Fuel injection control device for internal combustion engine," Dec. 261995 , uS Patent 5,477,831.

[10] C. Schuh, T. Steinkopff, A. Wolff, and K. Lubitz, "Piezoceramic multilayer actuators for fuel injection systems in automotive area," in Proceedings-SPIE the international society for optical engineering. International Society for Optical Engineering; 1999, 2000, pp. 165-175.

[11] I. Chopra, "Review of state of art of smart structures and integrated systems," AIAA journal, vol. 40, no. 11, pp. 2145-2187, 2002.

[12] K. Ma, "Vibration control of smart structures with bonded pzt patches: novel adaptive filtering algorithm and hybrid control scheme," Smart Materials and Structures, vol. 12, no. 3, p. 473, 2003.

[13] S. Park, C.-B. Yun, Y. Roh, and J.-J. Lee, "Pzt-based active damage detection techniques for steel bridge components," Smart Materials and Structures, vol. 15, no. 4, p. 957, 2006.

[14] D. Balma, A. Lamberti, S. L. Marasso, D. Perrone, M. Quaglio, G. Canavese, S. Bianco, and M. Cocuzza, "Piezoelectrically actuated mems microswitches for high current applications," Microelectronic Engineering, vol. 88, no. 8, pp. 2208-2210, 2011.

[15] H. J. Pahk, D. S. Lee, and J. H. Park, "Ultra precision positioning system for servo motor-piezo actuator using the dual servo loop and digital filter implementation," International Journal of Machine Tools and Manufacture, vol. 41, no. 1, pp. 51-63, 2001.

[16] H. Liu, B. Lu, Y. Ding, Y. Tang, and D. Li, "A motor-piezo actuator for nano-scale positioning based on dual servo loop and nonlinearity compensation," Journal of Micromechanics and microengineering, vol. 13, no. 2, p. 295, 2003.

[17] M.-H. Chiang, C.-C. Chen, and T.-N. Tsou, "Large stroke and high precision pneumatic-piezoelectric hybrid positioning control using adaptive discrete variable structure control," Mechatronics, vol. 15, no. 5, pp. 523-545, 2005.

[18] D. Shen, J.-H. Park, J. Ajitsaria, S.-Y. Choe, H. C. Wikle III, and D.-J. Kim, "The design, fabrication and evaluation of a mems pzt cantilever with an integrated si proof mass for vibration energy harvesting," Journal of Micromechanics and Microengineering, vol. 18, no. 5, p. 055017, 2008.

[19] D. Shen, J.-H. Park, J. H. Noh, S.-Y. Choe, S.-H. Kim, H. C. Wikle, and D.-J. Kim, "Micromachined pzt cantilever based on soi structure for low frequency vibration energy harvesting," Sensors and actuators A: physical, vol. 154, no. 1, pp. 103-108, 2009.

[20] X. Chen, S. Xu, N. Yao, and Y. Shi, "1.6 v nanogenerator for mechanical energy harvesting using pzt nanofibers," Nano letters, vol. 10, no. 6, pp. 2133-2137, 2010

[21] Y. Qi, J. Kim, T. D. Nguyen, B. Lisko, P. K. Purohit, and M. C. McAlpine, "Enhanced piezoelectricity and stretchability in energy harvesting devices fabricated from buckled pzt ribbons," Nano letters, vol. 11, no. 3, pp. 1331-1336, 2011

[22] H. Yu, J. Zhou, X. Yi, H. Wu, and W. Wang, "A hybrid micro vibration energy harvester with power management circuit," Microelectronic Engineering, vol. 131, pp. 36-42, 2015.

[23] M. T. Todaro, F. Guido, V. Mastronardi, D. Desmaele, G. Epifani, L. Algieri, and M. De Vittorio, "Piezoelectric mems vibrational energy harvesters: Advances and outlook," Microelectronic Engineering, 2017.

[24] W.-H. Wu, K.-C. Kuo, Y.-H. Lin, and Y.-C. Tsai, "Non-contact magnetic cantilever-type piezoelectric energy harvester for rotational mechanism," Microelectronic Engineering, vol. 191, pp. 16-19, 2018.

[25] F.-H. Ko, Y.-C. Hsu, M.-T. Wang, and G.-w. S. Huang, "Fabrication of a gas sensor with a piezoelectric pzt film deposited by a novel hydrothermal microwave-assisted annealing," Microelectronic engineering, vol. 84, no. 5-8, pp. 1300-1304, 2007.

[26] J. E. Griffith and D. A. Grigg, "Dimensional metrology with scanning probe microscopes," Journal of Applied Physics, vol. 74, no. 9, pp. R83R109, 1993.
[27] T. Michels and I. W. Rangelow, "Review of scanning probe micromachining and its applications within nanoscience," Microelectronic Engineering, vol. 126, pp. 191-203, 2014.

[28] L.-n. Sun, S.-y. Sun, W.-b. Rong, and H.-g. Cat, "Macro/micro manipulator based on pzt actuator [j]," Journal of Harbin Institute of Technology, vol. 1, p. 004, 2004.

[29] L. Chang, X. Huang, and M. Wang, "Research on pzt bimorph microgripper system," in Intelligent Control and Automation. IEEE, 2010, pp. 5498-5502.

[30] M. E. Fermann, A. Galvanauskas, and G. Sucha, Ultrafast lasers: Technology and applications. CRC Press, 2002, vol. 80.

[31] A. Bienaimé, V. Chalvet, C. Clévy, L. Gauthier-Manuel, T. Baron, and M. Rakotondrabe, "Static/dynamic trade-off performance of pzt thick film micro-actuators," Journal of Micromechanics and Microengineering, vol. 25, no. 7, p. 075017, 2015.

[32] R. G. Ballas, Piezoelectric multilayer beam bending actuators: Static and dynamic behavior and aspects of sensor integration. Springer Science \& Business Media, 2007.

[33] E. E. Aktakka, R. L. Peterson, and K. Najafi, "Thinned-pzt on soi process and design optimization for piezoelectric inertial energy harvesting," in Solid-State Sensors, Actuators and Microsystems Conference. IEEE, 2011, pp. 1649-1652.

[34] F. Dausinger, H. Hügel, and V. Konov, "Micro-machining with ultrashort laser pulses, from basic understanding to technical application," in Proc. of SPIE Vol, vol. 5147, 2003, p. 107.

[35] N. Uppal, P. S. Shiakolas, and S. Priya, "Micromachining of pzt using ultrafast femtosecond laser," Ferroelectrics Letters Section, vol. 32, no. 3-4, pp. 67-77, 2005

[36] D. Belharet, A. Benouhiba, M. Rakotondrabe, and C. Clévy, "Direct process flow fabrication for piezoelectric actuators based on thinned pzt technology," in International Conference on Micro and Nano Engineering MNE17, no. 43rd, Braga (Portugal), 18-22 septembre 2017. 